\title{
SUPPORTING TEACHERS AND PARENTS WITH MOBILE TECHNOLOGY TO TEACH READING
}

\author{
Roberto Araya \\ Center for Advanced Research in Education, Institute of Education, Universidad de Chile. Periodista \\ José Carrasco Tapia $N^{\circ} 75$, Santiago, Chile
}

\begin{abstract}
Teaching to read is a slow and complex process. It is very challenging as the student must recycle neural resources evolutionary designed for other tasks. That takes a lot of practice and perseverance. To top it all, there are two rival strategies for teaching reading that have been at war for many decades. On the other hand, unlike older students, it is much more complex to record evidence of progress since students cannot easily answer multiple-choice tests nor written open-ended ones. Much is based on observation in class as students work. Additionally, parental support is critical at that age. In this paper, we describe an app that was voluntarily adopted by 1,235 schools that supported teachers and parents to track the progress of students. We found a very rapid adoption of the app, a surprisingly big imbalance between the intended and implemented curriculum, much lower student performance in writing than in reading and oral communication, and strikingly great participation and enthusiasm of parents in creating videos to share with other parents where they show playful strategies to teach reading to their kids.
\end{abstract}

\section{KEYWORDS}

Mobile, Cloud Computing, Pedagogical Approach, Social Network

\section{INTRODUCTION}

Teaching to read is the first pillar of education. Everything else is based on developing this skill. However, it is a slow and complex process. An example of this difficulty is the illiteracy that still exists. Illiteracy costs the world economy more than USD 1 trillion annually in direct costs (World Literary Foundation, 2015). Among the main difficulties is the fact that reading is very challenging as the student must reconvert neural resources evolutionary designed for other tasks (Dehaene, 2005). This takes a lot of practice and perseverance. To top it all, there are two rival strategies to teach reading, which have been generating a pedagogic dispute for nearly a century, 
and have been described as the "reading wars". While one of them is effective according to empirical evidence, many teachers and parents use the wrong strategy or an inefficient mix of them. Thus, in 1997, the U.S. Congress asked the National Institute of Child Health and Human Development (NICHD), to work with the U.S. Department of Education in establishing a National Reading Panel that would evaluate existing research and evidence to find the best ways of teaching children to read. The National Reading Panel reviewed all the research available (more than 100,000 reading studies) on how children learn to read, and concluded that the best approach to reading instruction is one that incorporates explicit instruction in phonemic awareness, systematic phonics instruction, methods to improve fluency, and ways to enhance comprehension. However, the last Programme for International Student Assessment PISA 2018 (OECD, 2018a) study concluded that around the world, the share of 15-year-old students, in grade 7 and above, who reached a minimum level of proficiency in reading (at least Level 2 on the PISA scale) ranged from close to $90 \%$ in Beijing, Shanghai, Jiangsu and Zhejiang (China), Estonia, Macao (China) and Singapore, to less than 10\% in Cambodia, Senegal and Zambia. Another recent report, Adams et al, 2020, concludes that "reading achievement isn't improving. Too many students - particularly students who are living in poverty or are of color - enter grade 3 unable to read or unable to read as well as they should." In the U.S. almost $40 \%$ of the elementary school day is devoted to the subjects of English, reading, and language arts, all contributing towards the development of literacy (USDOE, 1997), but 33\% of students in Grade 4 score below a basic level of proficiency in reading, as measured by National Assessment of Educational Proficiency (NAEP) tests (Hollands et al, 2013).

On the other hand, unlike older students, it is much more complex to record evidence of progress since students cannot easily answer multiple-choice tests nor written open-ended ones. Much is based on direct observation in class as students work. Additionally, one of the great pending challenges is to track how teachers and parents teach reading, if they follow the effective strategies empirically demonstrated by those thousands of studies. While education ministries are increasingly designing evidence-based curricula and texts, these strategies are not always used in classrooms and homes. There is a big gap between the intended curriculum designed by the Ministry curriculum developers and the implemented and the attained curriculum on schools (OECD, 2018b). Moreover, there is a lack of on-time measurement instruments to inform principals, superintendents, curriculum developers and administrators of the Ministry of Education. In most countries, standardized measurements begin at the end of fourth grade, but this is too late to give timely feedback. In some countries there are measurements on samples of the population at the end of second grade, but they are also too late. They only measure a small sample of students due to the cost of measurement in students who still cannot follow the typical instructions of the regular standardized tests. The strategy required to achieve timely feedback is to be able to measure and monitor weekly progress of all first grade students.

Another difficulty is the fact that parents' effort is critical for students learning outcomes (De Fraja et al., 2005). It is sometimes more critical than students' effort and school effort, and this is particularly true for elementary school boys. At age 7, parent effects explain $29 \%$ of the variance in attainment, while school effects explain only 5\% of the variance (Gross, 2017). Therefore, foster their active participation in their children's learning is key. Moreover, parents' expectations are also critical. Given that parents of the lowest socioeconomic status (SES) segments have average expectations of attainment much lower than the average expectations of the rest of the parents (Araya et al., 2017, Child Trends Databank, 2015), then it is very important to engage parents of the low SES segment. Parents give enormous value to learning 
IADIS International Journal on WWW/Internet

to read. What parents want and value (Zeehandelaar et al., 2013), is a strong core curriculum in reading and mathematics. However, according to Willingham (2015) parents have very little idea how their kids learn to read. They don't think much about reading comprehension. They assume that if a kid can accurately say the words on the page out loud, then she is reading. They also don't know how to motivate their kids to read.

Technology can help to support teachers to teach and implement the curriculum. There are several experimental and quasi-experimental studies that show the potential of Performance Support Systems (Araya, 2019). For example, in Araya et al. (2019), a yearlong RCT with 48 fourth grade classes showed half a year of extra learning in mathematics for the treatment condition that used a cloud based platform. However, after a systematic review and meta-analysis of numerous studies conducted comparing reading from paper and electronic sources, Clinton 2019, concludes that readers may be more efficient and aware of their performance when reading from paper compared to screens. Other studies show some positive impacts using smartphones. For example, Chee et al 2017, has tested impact of smartphone on students learning in small samples. They found higher scores on tests after four consecutive weeks of intervention. Thus the empirical evidence is mixed. In a recent study, the Asian Development Bank follows (Smart et al., 2018), concludes that all the evidence suggests that for most education systems - at least for the foreseeable future - digital resources will be used alongside traditional printed resources in what is often described as "blended learning".

Fifty years ago a computer occupied an entire floor of a building. It was clearly not possible at all to use computers in the classroom. Today a notebook has much more computing power and now it can fit in a backpack. But it is still uncomfortable for a teacher to walk around the classroom with a notebook guiding the students. This barrier radically disappears with a smartphone. It's light, small, ubiquitous, and cheap. It also has enormous computational power and great connectivity. Ideally, it should be an invisible device that constantly listens to the teacher, records relevant events, and gives her timely feedback that allows her to improve her impact on students' learning.

Smartphones are already making having a huge impact on several areas of the economy. The mobile phone technology not only has created a positive impact on several areas but is already contributing in poverty reduction (Londhea et al, 2014). Additionally, smartphones are now ubiquitous all over the world. A recent Gallup World Poll (Klapper et al, 2020) shows that 83 percent of adults in developing economies have a mobile phone as of 2018. Farmers use mobile phones to research crop prices and marketing opportunities. For example, the arrival of mobile coverage has been linked to higher consumption and reduced poverty in rural Peru. A recent 2019 World Bank Report (2020), shows that people are increasingly using smartphones, tablets, and other portable electronic devices to work, organize their finances, secure and heat their homes, and have fun.

In this paper, we propose a blended strategy, where only teachers, principals, educational administrators, and parents use their smartphones, but not students. Thus the contribution of this paper is to explore the impact of mobile technology when teachers, administration, and parents use it to teach students, to track their learning and to disseminate teaching strategies. 


\section{SUPPORTING TEACHERS}

A major challenge in education is how to improve teaching. One possible strategy is the use of Performance Support Systems (Reynolds et al, 1995, Araya et al, 2015, Araya, 2019). This kind of systems provide real time support to users, similarly as waze or google maps support drivers to reach their location. In this paper we present the application for a semester of the ConectaIdeas Express app that was added to ConectaIdeas, a teaching platform. This is a Learning Managing Platform hosted in the cloud and that has proved on an RCT to be effective for teaching mathematics for fourth graders (Araya et al., 2019). The app supports teachers in the classroom to perform evaluation with quick questions, called exit tickets (Araya, 2020a). These are formative assessments that give teachers a way to quickly understand how well their students comprehend the material they are learning during class time.

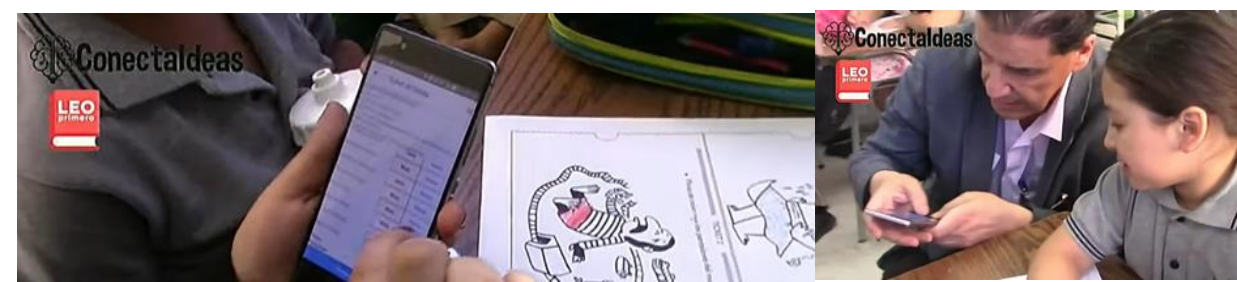

Figure 1. The ConectaIdeas Express app used by teachers to assess student learning on different activities all linked to official curriculum Learning Objectives

The app also allows teachers to have constant monitoring of each student learning and a concept map with the curriculum coverage. It displays a tree with the coverage and performance on the official curriculum Strands and Learning objective, as shown in figure 2. It also has a geographic information system that integrates a social network with its parents and with the rest of the school community in its district and region. Teachers manage the app, but parents can get maps and information at the course level (not individual student) on their smartphones. 

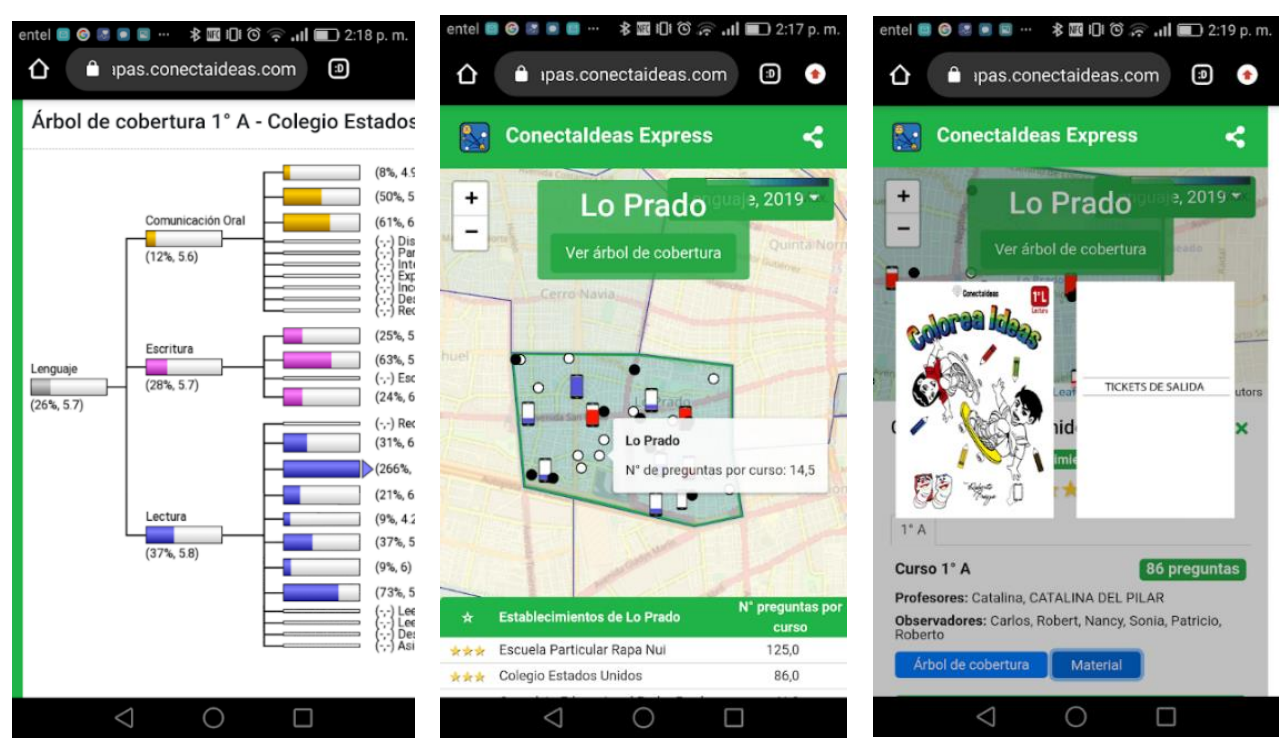

Figure 2. Left: a concept map tree showing each of the three strands with its coverage and performance, and each of the Leaning Objectives with its corresponding coverage and performance. Center:

ConectaIdeas Express map with the schools of the Lo Prado district, and with a small smartphone showing the level of use of the app on each school. The activity of parents is also shown on this map. Right: material that each parent and kid can access on the place of his school on the map

The ConectaIdeas Express App allows teachers to use exit tickets without necessarily having to have an Internet connection at the time of the evaluation. Teachers can save the information on their smartphone and upload it later on, when they have Internet access.

The ConectaIdeas Express app was offered to schools on June 1st, 2019, to a universe of approximately 5,000 schools. Since the exit tickets loaded in the app were aligned to a specific textbook offered by the Ministry, and only 2,500 schools were effectively using that textbook according to a Ministry of Education Survey, then almost half of the potential schools adopted the app. Every week an e-mail was sent to schools principals and teachers describing the app and how to use it. By December 2019 1,235 schools adopted it. The adoption curve is shown in Figure 1. At the end of the year, 568,524 students' answers were evaluated and registered by their teachers. The average number of exit tickets posed by teachers was 22 . This means, that each teacher posted an exit ticket on 22 sessions. It is important to mention that July has two weeks of winter vacation and that there is also an extra week of vacation in September. Moreover, due to national strikes in October and November, 3 weeks were lost. This means, that on average each teacher used the app in two sessions per week.

In early December 2019, an online anonymous questionnaire was sent to 1,000 teachers and principals who had used ConectaIdeas Express. Among the questions was whether ConectaIdeas Express was easy to use. 86 responses were received. $90.5 \%$ of respondents replied that they agreed that it was easy to use. 


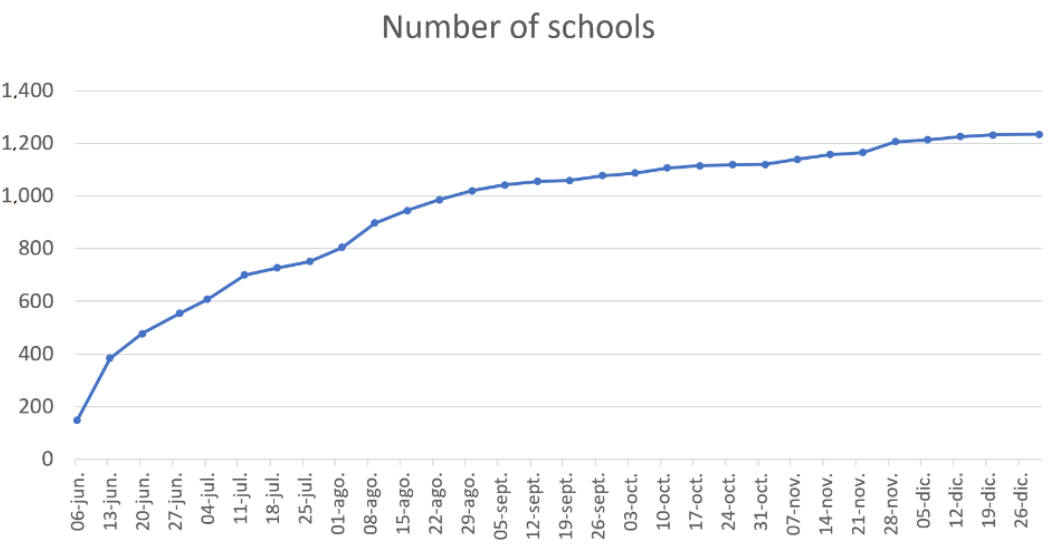

Figure 3. Number of schools that adopted the Mobile ConectaIdeas App from June to December 2019

One of the most surprising findings was the great imbalance in the learning objectives in the activities carried out by teachers. Out of the 26 Learning Objectives of the curriculum, 29.1\% of the tickets posted by teachers correspond to the most used Learning Objective. Moreover, the most fundamental Learning Objectives, OA 10: "read independently and understand simple non-literary texts", was not used. Thus a remedial strategy was implemented in order to revert this situation. The Ministry of Education implemented A National Reading Day where schools were asked to do exit tickets that use that Learning Objective. This fact illustrate the benefit of on line monitoring. The use of the cloud monitoring system allowed Ministry officials to monitor in real time what was going on at the schools and detect a big gap between the intended and implemented curriculum, and therefore implement actions to revert part of this gap.

Number of Answers for Curriculum Learning Objectives (OA)

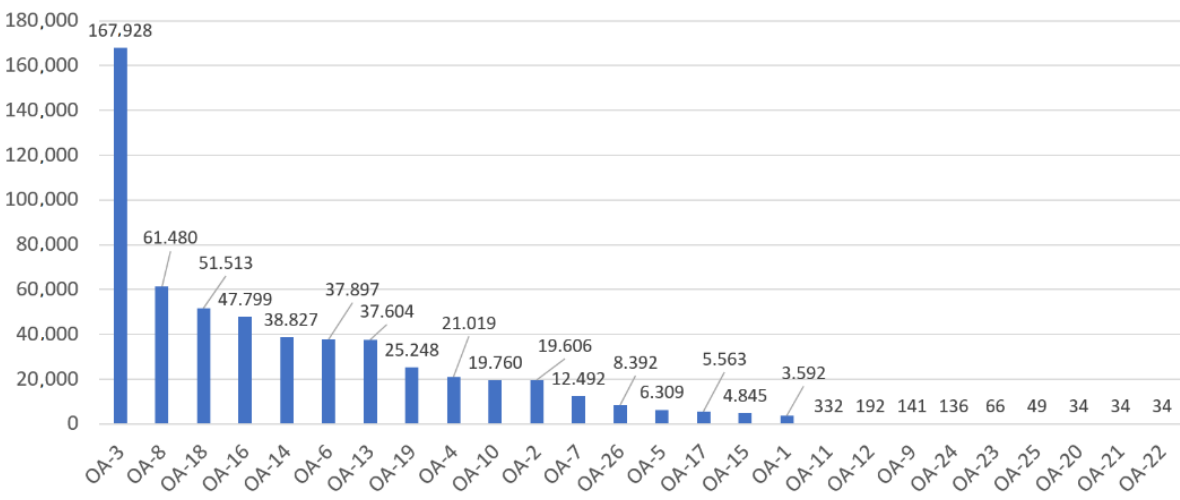

Figure 4. Number of students answers for each of the Learning Objectives (OA) of the first grade language curriculum 
IADIS International Journal on WWW/Internet

Most of the tickets posted by teachers belong to the Reading strand, and this was permanently so, as shown in figure 5. Writing was the strand where performance was the lowest as shown in Figure 6. Moreover, Learning Objective OA 13 "Experiment with writing to communicate facts, ideas and feelings", obtained significantly lower assessment than the rest of the Learning Objectives, as shown in Figure 7. An interesting finding is that on those classes where the teacher did more tickets, above the median, the performance in writing was $79 \%$, which is higher than on the other classes where the performance was $77.9 \%$. This difference is statistically significant. This difference was particularly higher in the Learning Objective OA 6 "Understand texts applying reading comprehension strategies".

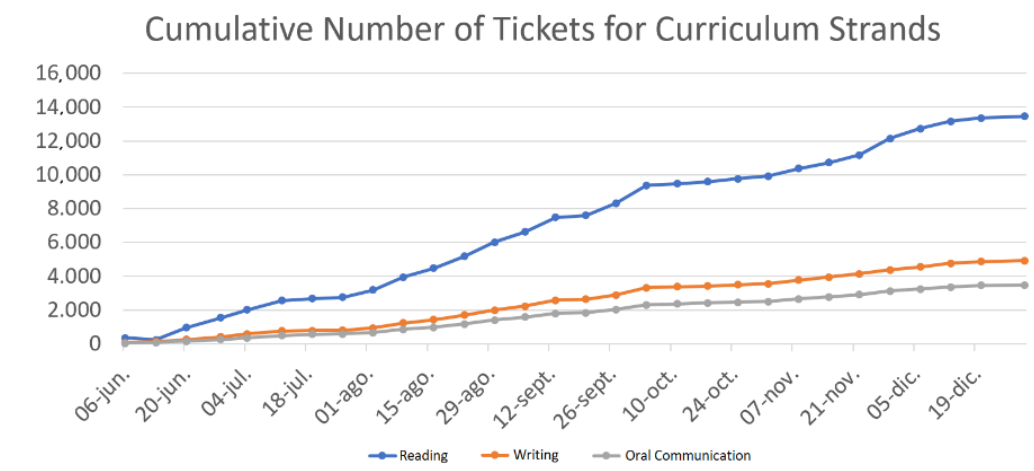

Figure 5. Accumulative number of question posed by the teachers by the three curriculum strands, reading, writing and oral communication. Each strand contains several Learning Objectives

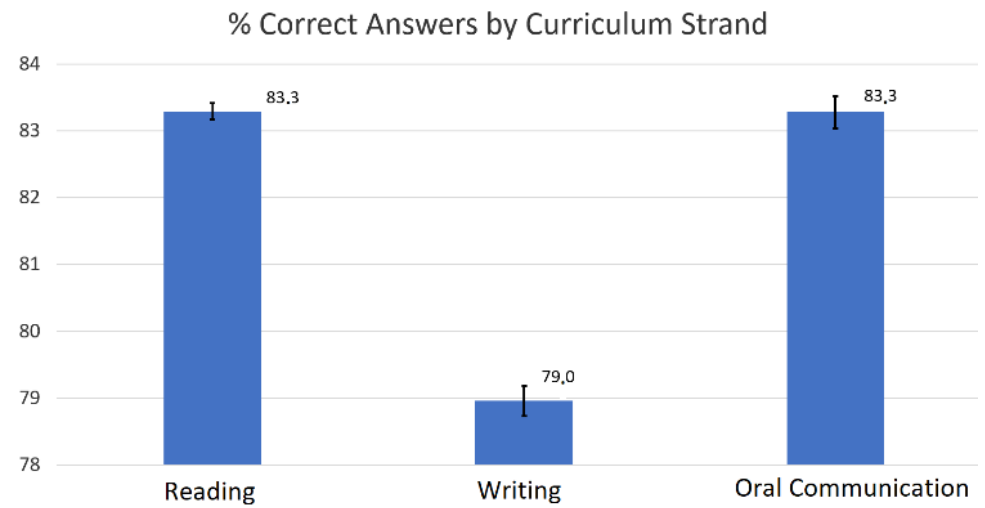

Figure 6. Percentage of correct answers for questions belonging to the three curriculum strands, reading, writing and oral communication 


\section{\% Correct Answers on the 7 Learning Objectives with Highest Use}

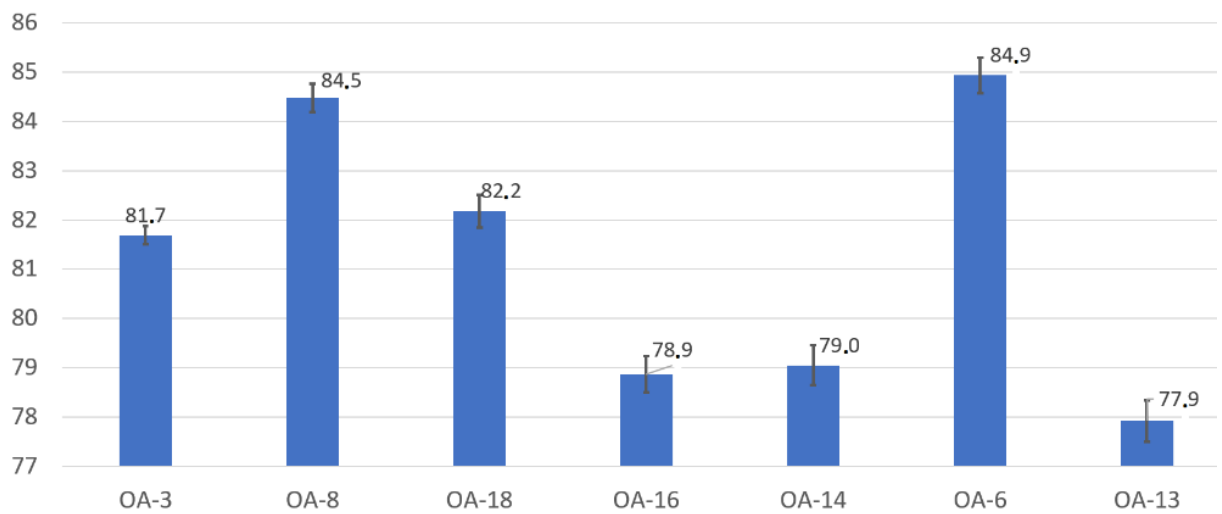

Figure 7. Percentage of correct answers for questions belonging to the most frequently used Learning Objectives

As mentioned before, from the data that was being gathered, authorities from the Ministry concluded that teachers practically were not asking questions to assess reading comprehension. Therefore, given the need to have an estimate of the level of the students' reading comprehension by the end of the year, the Ministry of Education implemented a National Reading Day that was specifically designed to measure reading comprehension. Four exit tickets were designed, in which the text gave instructions to paint some drawings. The instructions on what to paint ad what color had to be read by the students. In this way it was constituted as a recreational and artistic activity, but which was basically a reading comprehension test. All tickets measured reading comprehension, more specifically the Learning Objective OA10: "Read independently and understand simple non-literary texts". 144 schools participated, and of these schools, teachers registered 9,808 student responses, corresponding to the 4 tickets. $87.33 \%$ of the answers were evaluated as correct by the teachers. The speed of the evaluation was highly valued in the Ministry of Education. Normally it takes about a year to have feedback with tests designed by the educational authorities. Additionally, in the country there is no government test for first graders. Thus this test was the first time ever a test was implemented for first graders in the country.

The participation of the teachers has increased and also their interest in sharing strategies. This has meant the creation of a very active community, in which every week the Ministry sends emails with dissemination of testimonies and a web page (figure 8) that collects all the testimonies. 


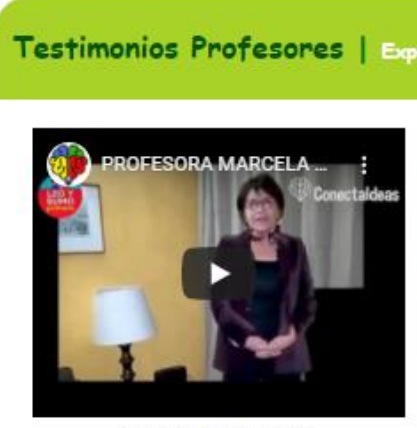

PROFESORA MARCEL DONOSO COMUNA LA RLOTIA - REGTÓN METROFOLTANA

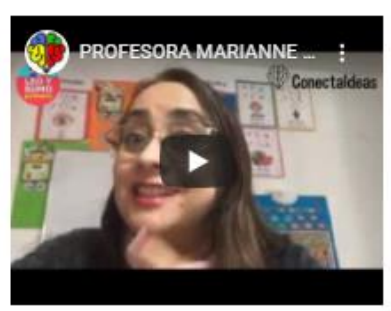

PROFESORA MARTANNE SANDOVA COLEGTO HTSSANO
COMLNA DE MQTCA - REGTÓN DE ARTCA Y PMETNACOTA

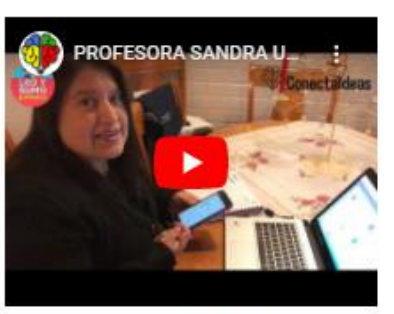

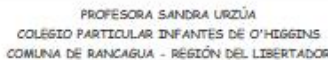
SERNABDO O' HEGGINS

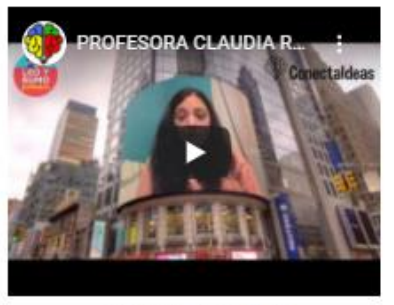

PROFESCRM OANDIA ROBLES COMUNA DE QUIRUE - REGTÓN DE VALPARATSO

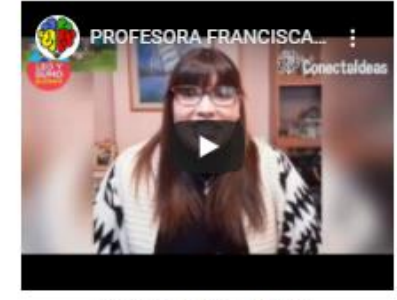

PROFESORA FRANCTSCA AHUMADA COMLNA DE QUTPUÉ - REGTÓN DE VALPARATSO

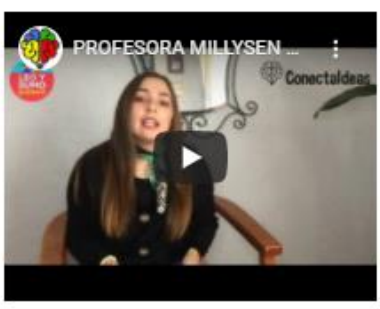

PROFESORA MDLYSSEN ROMERO COMUNA DE CURTCOÓ - REGEÓN DEL MAULE

Figure 8. Testimonials from teachers who share their teaching strategies with the entire teaching community in the country

\section{SUPPORTING PARENTS}

In order to attract and engage parents to support at home their kids' learning, videos of prototype activities were disseminated. These videos show strategies with games, dices and teddy bears to encourage phonemic awareness and reading comprehension. The games were recorded on videos and uploaded to the cloud together with an invitation to mothers, fathers and grandparents, to watch them. In two weeks, the videos had more than 4,000 views. The plan was to encourage parents to recreate the strategies at their homes, and also to modify the games and activities, and create new ones. It was also encouraged that they provided emotional support and motivation to their students, particularly to appreciate reading and writing. The idea was to get them to practice with their families with playful and social strategies. The goal was also to encourage parents to share their experiences and their inventions with other parents, and build a social network of parents of first graders. Thus a learning community between parents was created. They recoded short videos with their smartphones and uploaded to the ConectaIdeas map to share them. The Ministry of Education also implemented in a geographical region the First Breakfast with Parents for Reading. It was held in October 2019. 500 schools were invited to send one parent representing the school. Given the enormous interest of parents in participating that exceeded the capacity of the planned room, the Ministry of Education limited the participation to the first 160 schools that applied. Finally, 173 parents from different schools 
in the region attended the event, each one bringing their video recording. 98 videos were finally received and uploaded by their teachers to the ConectaIdeas map, as shown in figure 9 . These videos show the implementation of the proposed strategies: 80 videos show mother and student, 48 videos show word segmentation, 47 videos show home-grown educational games, 26 videos show teddy bears or glove puppets, and 12 videos show games with magic boxes.
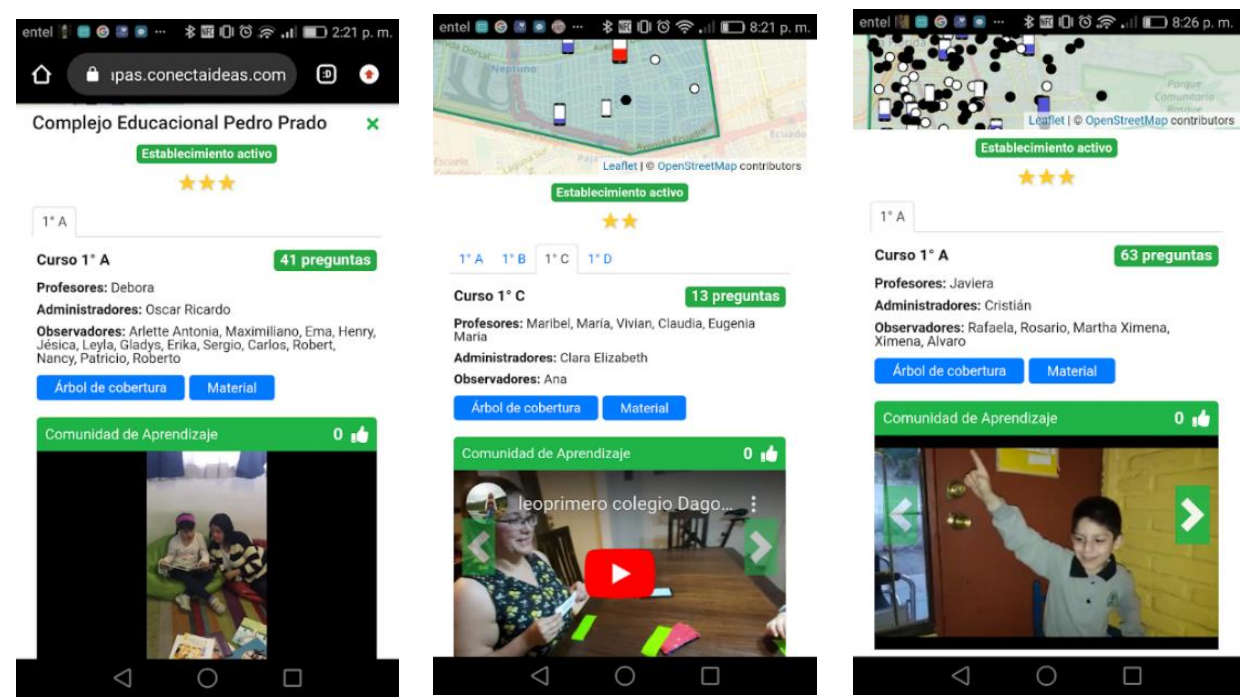

Figure 9. Screenshots of three videos designed and recorded by parents and uploaded on the ConectaIdeas map in order to share with other parents

In mid-October, educational videos made by parents were uploaded to the system (Araya, $2020 \mathrm{~b}$ ), in which they shared examples of homemade activities and teaching strategies. 98 schools from the most populated region submitted 98 parent-made videos to be shared during a public event. $82 \%$ of the videos showed a mother with her child learning to read or write, $49 \%$ showed word segmentation activities, $48 \%$ showed homemade educational games, and $26 \%$ showed activities using glove puppets. Experts rated the communication and educational quality of the videos. We found that a much higher proportion of videos involving glove puppets were rated as 'very good' when compared to the other types.

According to Willingham, 2017, there are three levels in reading comprehension: extract ideas from sentences, connect ideas across sentences, and build a general idea of what a text is about. After the First Breakfast with Parents, new activities using a coloring book implemented these strategies, and particularly the strategy to connect ideas across sentences. The coloring book, shown in Figure 2 right, is basically a list of exit tickets that the teacher can use. Several teachers and parents implemented them on classrooms and homes. We found that this is a very engaging mechanism for all the community. It is therefore a good tool for dissemination of strategies specially aimed to improve reading comprehension. However, much of this strategy is still work in progress.

In some schools the teachers handed out the color book ideas to work in the summer (from December 2019 to end of February 2020). The book begins with simple coloring activities. For example, paint a ball green. As activities progress, they are more demanding. They require reading and understanding logical instructions that include quantifiers and that prepare for 
IADIS International Journal on WWW/Internet

computational thinking. For example, in each box paint some blue balls. On the other hand, every sheet comes in a pair, called sheet A and sheet B. On sheet A the student must paint according to the instruction. On sheet B the student must create an instruction for a classmate to read and paint according to that instruction. In several courses all students will complete the book during summer break, and parents were very pleased with the enthusiasm shown by the students. Two examples of writing instructions (code) with quantifiers are shown in Figure 10. In one case on the left the student wrote: "In two boxes he paints at least three brown balls." In the case on the right, the second student wrote: "Paint a red ball from each box."
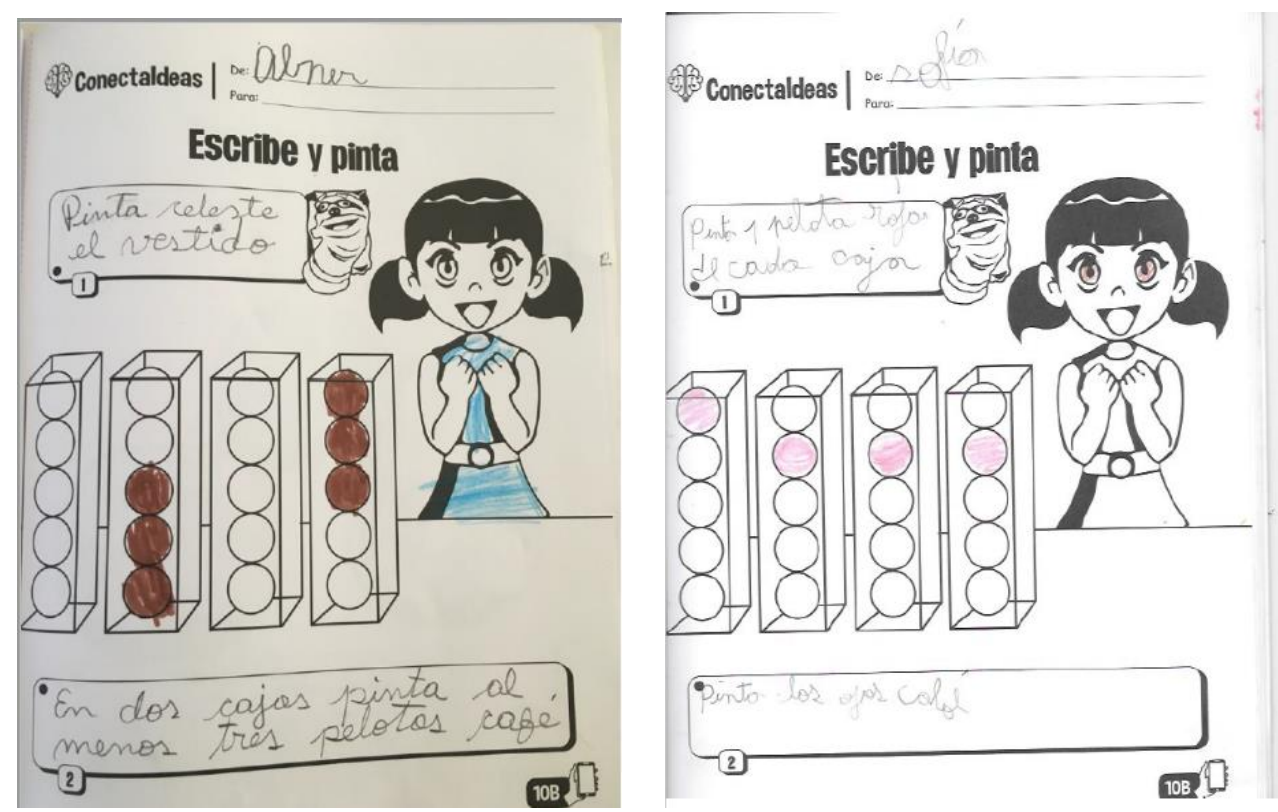

Figure 10. Examples of activities of writing instructions for coloring performed by two students on summer vacation

\section{CONCLUSION}

Teaching to read is very challenging as the student must reconvert neural resources evolutionary designed for other tasks. On the other hand, unlike older students, it is much more complex to record evidence of progress since students cannot easily answer multiple-choice tests nor written open-ended ones. Much is based on observation in class as students work. Additionally, parental support is critical at that age. In this paper we describe the use of mobile technology to implement a support system for teachers and parents to teach reading. After a semester of implementation, 1,235 school voluntarily adopted mobile technology to support teaching to read to 30,158 students. This is a unique experience that shows the potential of mobile technology to teach reading to first graders. This is almost $50 \%$ of the schools that were effectively using the textbook to teach reading offered by the Ministry of Education. The ConectaIdeas Express app was designed to support that textbook. This fact shows a very fast adoption curve. On average, 
each teacher used for 22 sessions, posting exit tickets at the final part of the session. This means that it was used twice a week. A survey to teachers showed that they found it easy to use.

Parents also used the app to access information about the progress on the coverage of the curriculum and to record and share videos showing strategies that they implemented with their kids. The strategy of creating a community of parents to implement games in their homes, innovate them, and share them in the ConectaIdeas map, was very attractive. Surprisingly, it produced much more participation than expected.

A great benefit of the mobile app and of displaying the information in a geographical system with the advances in performance and curriculum coverage by school, district and region, was that it allowed early detection of large gaps between the intended curriculum and the implemented one. That allowed taking corrective actions. Other findings will allow for the adaptation of strategies, school textbooks, exit tickets and materials for the coming years. Almost 600,000 students' answers were assessed, which made possible to detect Learning Objectives with much weaker performance than the other Learning Objectives. This information is very important to adapt strategies for new textbooks, materials and teacher professional development seminars. Moreover, the accumulated data reveal that there is an important gender gap in reading, and that it is bigger in students from the lowest SES and it is particularly bigger in rural schools (Araya, 2020c).

The main advantage of the ConectaIdeas Express app is to create a community of teachers and parents who share strategies to improve teaching and student learning. On the other hand, it is an enormous tool for monitoring in real time how the curriculum is being implemented throughout the country as a whole, and also disaggregated by regions, communes and schools. Each authority in charge of a region or commune can see in real time the progress and coverage for each of the strands and the learning objectives of the curriculum.

An important limitation is the cultural change that requires using tickets in each class and making sure to upload them to the platform. Part of this difficulty is due to the fact that there is more than one text that circulates in schools and the tickets are adjusted only to the official text of the Ministry of Education.

This app and its implementation show that using mobile technology in teaching reading to first grade students is a great opportunity for effective improvement. This is a blended strategy, where teachers, principals, educational administrators, and parents use their smartphones to track students' learning and share their teaching experiences. In 2020 the Ministry of Education has already started implementing it also for first and second grade.

\section{ACKNOWLEDGEMENT}

Support from ANID/ PIA/ Basal Funds for Centers of Excellence FB0003 is gratefully acknowledged, and from María Jesús Honorato from the Curriculum Unit of the Ministry of Education of Chile. 
IADIS International Journal on WWW/Internet

\section{REFERENCES}

Adams, M., Fillmore, L., Goldenberg, C., Oakhill, J., Paige, D., Rasinski, T., \& Shanahan, T., 2020. Comparing Reading Research to Program Design: An Examination of Teachers College Units of Study

Araya, R.; Gormaz, R.; Bahamondez, M.; Aguirre, C.; Calfucura, P.; Jaure. P.; Laborda, C. 2015. ICT supported learning rises math achievement in low socio economic status schools. 10th European Conference on Technology Enhanced Learning. Lecture Notes in Computer Science, Volume 9307, pp 383-388. Springer.

Araya, R., Gormaz, R., Ulloa, O., 2017. For which socioeconomic segments are parental expectations of educational attainments more sensitive to their children performance? Proceedings of the 6th International Conference on Sustainability, Technology and Education, Sydney, Australia, pp 51-58. http://www.iadisportal.org/digital-library/for-which-socioeconomic-segments-are-parentalexpectations-of-educational-attainment-more-sensitive-to-their-children-performance

Araya R., 2019. Teacher Training, Mentoring or Performance Support Systems?. In: Nazir S., Teperi AM., Polak-Sopińska A. (eds) Advances in Human Factors in Training, Education, and Learning Sciences. AHFE 2018. Advances in Intelligent Systems and Computing. Springer, Cham. Vol 785, pp 306-315.

Araya, R.; Arias Ortiz, E.; Bottan, N.; Cristia, J., 2019. Does Gamification in Education Work? Experimental Evidence from Chile. IDB WORKING PAPER SERIES No IDB-WP-982 InterAmerican Development Bank

Araya, R. 2020a. Mobile Performance Support System for Teachers and Parents Teaching First Graders to Read. 16th Mobile Learning 2020 conference proceedings. pp 47-54 http://www.iadisportal.org/digital-library/mobile-performance-support-system-for-teachers-andparents-teaching-first-graders-to-read

Araya, R. 2020b. A territorial learning ecosystem for parents' participation and cooperation. 5th conference on Smart Learning Ecosystems and Regional Development SLERD 2020

Araya R. 2020c. Early Detection of Gender Differences in Reading and Writing from a Smartphone-Based Performance Support System for Teachers. In: Vittorini P., Di Mascio T., Tarantino L., Temperini M., Gennari R., De la Prieta F. (eds) Methodologies and Intelligent Systems for Technology Enhanced Learning, 10th International Conference. MIS4TEL 2020. Advances in Intelligent Systems and Computing, vol 1241. Springer, Cham.

Chee, K.; Yahaya, N.; Ibrahim, N., 2017. Effectiveness of mobile learning application in improving reading skills in Chinese language and towards post-attitudes. International Journal of Mobile Learning and Organisation 11(3):210-225

Child Trends Databank, 2015. Parental expectations for their children's academic attainment. Online at: http://www.childtrends.org/?indicators=parental-expectations-for-their-childrens-academicattainmen

Clinton, V. 2019, Reading from paper compared to screens: A systematic review and meta-analysis. Journal of Research in Reading. Vol 42. Issue 2: 288-325

Hollands, F.; Pan, Y.; Shand, R.; Cheng, H.; Levin, H.; Belfield, C.; Kiefler, M.; Bowden, A.; Hanisch-Cerda, B. 2013. Improving Early Literacy: Cost-Effectiveness Analysis of Effective Reading Programs. Center for Benefit-Cost Studies of Education Teachers College, Columbia University.

De Fraja, G.; Oliveira, T.; Zanchi, S, 2005. Must Try Harder. Evaluating the Role of Effort in Educational Attainment. Centre for Economic Policy Research Discussion Paper No. 5048

Dehaene, S. 2005. Evolution of human cortical circuits for reading and arithmetic: The "neuronal recycling” hypothesis. In S. Dehaene , J . R. Duhamel , M . Hauser , \& G . Rizzolatti (Eds .), From monkey brain to human brain ( pp . 133 - 157). Cambridge, MA: MIT Press.

Gross, J. 2017. Parental Engagement How to make a real difference. https://cdn.oxfordowl.co.uk/2017/09/05/12/40/32/855/bp_gross_parentalengagement.pdf 
Klapper, L.: Mobile phones are key to economic development. Are women missing out? Brookings https://www.brookings.edu/blog/future-development/2019/04/10/mobile-phones-are-key-toeconomic-development-are-women-missing-out/ , last accesses 2020/02/04

Londhea, B., Radhakrishnanb, S., Divekar, R. 2014. Socio Economic Impact Of Mobile Phones On the Bottom Of Pyramid Population- A Pilot Study. Procedia Economics and Finance 11, 620 - 625(

National Reading Panel, 2000. Teaching Children To Read: An Evidence-Based Assessment of the Scientific Research Literature on Reading and Its Implications for Reading Instruction

OECD, 2018a. PISA 2018 Results. What Students Know and Can Do Vol I. OECDiLibrary.

OECD, 2018b, Future of Education and Skills 2030: Curriculum Analysis. Bridging curriculum design and implementation, 8th Informal Working Group (IWG) Meeting. Online at: https://www.oecd.org/education/2030project/contact/Bridging_curriculum_redesign_and_implementation.pdf

Reynolds, A.; Araya, R. 1995. Building Multimedia Performance Support Systems. McGraw-Hill, New York.

Smart, A.; Jagannathan, S. 2018, Textbook Policies in Asia Development, Publishing, Printing, Distribution, and Future Implications. Asian Development Bank

U.S. Department of Education, Office of Educational Research and Improvement. 1997. Time spent teaching core academic subjects in elementary schools: Comparisons across community, school, teacher and student characteristics. Retrieved from: http://0nces.ed.gov.opac.acc.msmc.edu/pubs/97293.pdf

Willingham, D., 2017. The Reading Mind: A Cognitive Approach to Understanding How the Mind Reads. Jossey-Bass.

Willingham, D., 2015. Raising Kids who Read. What Parents and Teachers Can Do. Jossey-Bass.

World Bank Report. The Changing Nature of Work. http://documents.worldbank.org/curated/en/816281518818814423/pdf/2019-WDR-Report.pdf, last accesses 2020/02/04

Zeehandelaar, D. and Winkler, A., 2013. What Parents Want: Education Preferences and Trade-Offs. Thomas B. Fordham Institute. 